\title{
In-Vivo Anti-Hyperlipidemic Activity and Preliminary Phytochemical Screening of Canephora robusta
}

\author{
Kishan Pavani Jankuti', Anusha Govindula2*, Rajkumar Jampala', Mohammad Arif Pasha ${ }^{3}$, \\ Aligeti Sravan Kumar ${ }^{1}$, Sunayana Soorammagari ${ }^{2}$, Chinnela Satish ${ }^{4}$, Mahankali Naga Ganesh ${ }^{5}$ \\ ${ }^{1}$ Department of Pharmaceutics, Vaageswari College of Pharmacy, Karimnagar, India \\ ${ }^{2}$ Department of Pharmacology,Vaageswari College of Pharmacy, Karimnagar, India \\ ${ }^{3}$ Department of Pharmaceutical Chemistry, Vaageswari College of Pharmacy, Karimnagar, India \\ ${ }^{4}$ Department of Clinical Pharmacy, Vaageswari College of Pharmacy, Karimnagar, India \\ ${ }^{5}$ Department of Pharmaceutics, Geethanjali College of Pharmacy, Hyderabad, India \\ Email: ^anu.govindula@gmail.com
}

How to cite this paper: Jankuti, K.P. Govindula, A., Jampala, R., Pasha, M.A., Kumar, A.S., Soorammagari, S., Satish, C. and Ganesh, M.N. (2020) In-Vivo Anti-Hyperlipidemic Activity and Preliminary Phytochemical Screening of Canephora robusta. American Journal of Molecular Biology, 10, 44-50.

https://doi.org/10.4236/ajmb.2020.101004

Received: October 4, 2019

Accepted: December 8, 2019

Published: December 11, 2019

Copyright $\odot 2020$ by author(s) and Scientific Research Publishing Inc. This work is licensed under the Creative Commons Attribution International License (CC BY 4.0).

http://creativecommons.org/licenses/by/4.0/

\section{(c) () Open Access}

\begin{abstract}
The main aim of this study is to determine the anti-hyerlipidemic and anti-obesity activity of Canephora robusta in hyperlipidemia induced rats. Prepared coffee bean extract (GCE) was procured from the market which is unroasted and contains more quantity of caffeine and chlorogenic acid when compared to roasted coffee. Male albino Wister rats are fed with high fat diet (HFD) for weeks to induce hyperlipidemia in rats, which are divided into 4 groups with 4 animals in each group. Test GCBE was given in doses of 200 $\mathrm{mg} / \mathrm{kg}$ and $400 \mathrm{mg} / \mathrm{kg}$ to III and IV groups which are fed with HFD for 30 days. Then blood samples were collected through retro-orbital sinus by capillaries and serum is separated for analysis. The result obtained from lipid profile which includes total cholesterol, triglycerides, very low density lipoproteins, and low density lipoproteins shows the decreased level when compared to the hyperlipidemic control. This shows the significant reduction of total body weight $(\mathrm{p}<0.05)$ when given with dose of $200 \mathrm{mg} / \mathrm{kg}$ and $400 \mathrm{mg} / \mathrm{kg}$. The present study suggests that GCBE has anti-obesity and anti-hyperlipidemic activity, where $400 \mathrm{mg} / \mathrm{kg}$ is more effective to reduce the total body weight and lipid levels when compared to $200 \mathrm{mg} / \mathrm{kg}$. Further studies on this extract may lead to identify the possible mechanism of action and isolation of active principle from the same.
\end{abstract}

\section{Keywords}

Anti-Hyerlipidemic, Anti-Obesity, Lipoproteins Hyperlipidemia, 
Canephora robusta

\section{Introduction}

Nowadays obesity is the most prevailing conditions in world wide. Obesity is a disorder involving in excessive accumulation of body fat. It increases risk of diseases and health problems such as heart disease, diabetes, high blood pressure [1]. According to WHO overweight and obesity are defined as the abnormal fat accumulation that causes the risk to health [2]. Therefore, lifestyle changes such as exercise and eating healthy diet are the first line against high fat [3]. Hyperlipidemia is elevated lipid levels in blood. This is also leading to increased risk of heart diseases [4]. Coffee is a drink prepared from roasted and unroasted coffee beans, which is widely taken beverages all over the world [5]. Coffee canefora is better known as Coffee robusta which is classified as variety of $C$. canefora [6] Coffee robusta [unroasted green coffee beans] of the Rubiaceae family is rich in chlorogenic acid and caffeine called as green coffee beans. The roasting process of coffee bean reduces amount chlorogenic acid, which is thought to have health benefits [7]. People take green coffee for obesity, diabetes, high blood pressure, Alzheimer's disease and bacterial infections [8]. Green coffee bean is promising as an energy supplement which has chlorogenic acid active ingredient which is well known to reduce the cholesterol and triglyceride levels in serum [9]. It is found to have presence chemical constituents like green coffee which includes flavonoids, glycosides, alkaloids, tannins and phenols which are detected and proved by using standard methods [10]. Coffee bean extract appears to effectively suppress body fat and serum triglyceride levels through at least in part the decrease in fatty acid synthesis and the acceleration of fatty acid oxidation, showing that it may be a novel functional food material for suppressing fat deposition [11]. Antioxidant and radical scavenger activities of coffee beans can improve wound healing to control overexposure of oxidative stress in the wound bed. The coffee beans press cake has shown a lower commercial value; however it might gain value as thought of as a valuable biomass source of bioactive compounds interesting for the human health usage. Indeed, the residual coffee biomasses studied are able to improve the regeneration of damaged skin tissue, allowing new product development in the cosmetic and pharmaceutical industries [12].

\section{Materials and Methods}

\subsection{Plant Material}

Coffee bean powder of Canephora robusta was procured from the market.

\subsection{Plant Extract}

\subsubsection{Preparation of Aqueous Extract [12]}

The bean powder of Canephora robusta is soaked in water for 1 hour in a 
beaker. Then the powder is filtered by using filter paper. Then obtain extract is evaporated in water bath.

\subsubsection{Preparation of Alcoholic Extract [13]}

The bean powder of Canephora robusta is extracted with ethanol by the soxhlation method by using soxhlet apparatus. The extract was evaporated on a water bath until the solvent has been evaporated and the extract was completely dry and weighed and pure extract was obtained.

\subsection{Phytochemical Screening [14]}

All the chemicals used in the study were analytic graded. Chemical tests were carried out with alcohol and aqueous extract by adapting standard procedure.

\subsection{Experimental Animals}

Mature male albino Wistar rats of weight 150 - 200 gm were used for the experiment. Animals selected were free from diseases. Animals were housed in a temperature of $22^{\circ} \mathrm{C} \pm 1{ }^{\circ} \mathrm{C}$. At 12:12 hours light and dark cycle was maintained. All the animals were allowed to free access of water and feed off the normal pellet diet. The composition of atherogenic diet is used during the study. The experimental procedure and protocol used in the study were viewed by the Institutional Animal Ethical Committee (IAEC) No: (VCP/cology/10/11/2018) and were in accordance with the guidelines of the CPCSEA (VCP/cology/10/11/2018).

\subsection{Induction of Obesity}

In order to induce obesity and hyperlipidemia method reported by Bopanna et al. was followed by feeding the male Wistar albino male rats (150 - $200 \mathrm{~g})$ with high fat diet for 30 days. The composition of Atherogenic Diet was followed according to Yash Prashar et al. [15], the composition of the diet is included in Table 1. Acute toxicity studies were conducted in Wistar albino male rats as per OECD guidelines 423 [16]. The alcoholic extract of Canephora robusta was found

Table 1. Atherogenic diet used during the study [15].

\begin{tabular}{cccc}
\hline S. No. & Composition & Normal Diet (\%) & Atherogenic Diet (\%) \\
\hline 1 & Protein (Milk Powder) & 12 & 10 \\
2 & Carbohydrates (Wheat Powder) & 71 & 61 \\
3 & Sugar & 05 & 05 \\
4 & Fat (Butter) & 05 & 16 \\
5 & Salt & 04 & 04 \\
6 & Vitamin & 01 & 02 \\
7 & Fibres & 02 & 01 \\
8 & Cholesterol & - & 01 \\
& Total & $100 \mathrm{gm}$ & $100 \mathrm{gm}$
\end{tabular}


the safe dose at $4000 \mathrm{mg} / \mathrm{kg}$.

\subsection{Experimental Design}

Sixteen mature male albino Wistar rats were randomly grouped into 4 groups of 4 animals each.

Group 1: Normal control;

Group 2: Atherogenic/hyperlipidemic control;

Group 3: Standard control;

Group 4: Ethanolic extract of $200 \mathrm{mg} / \mathrm{kg}$ and $400 \mathrm{mg} / \mathrm{kg}$.

Group I rats are fed with Normal Diet and remaining three groups are fed with the high fat diet to induce obesity. Other $3^{\text {rd }}$ and $4^{\text {th }}$ groups are given with standard and test along with high fat diet. The standard used in this study is atorvastatin at a dose of $10 \mathrm{mg} / \mathrm{kg}$ for 1 week and group 4 is given with GCBE at doses of $200 \mathrm{mg} / \mathrm{kg}$ and $400 \mathrm{mg} / \mathrm{kg}$ through oral route using cannula for 1 week. The end of the experiment body weight of rats was recorded.

\subsection{Blood Sampling Analysis}

Blood was withdrawn by using heparinised capillaries from the retro-orbital sinus in overnight fasted animals and the obtained blood is centrifuged at 3000 rpm for 15 - 20 mins to obtain serum which was used to estimate the concentration of biochemical parameters TC, HDL, LDL, VLDL using the semi-auto analyser and relevant lipid profile kits.

\subsection{Statistical Analysis}

Appropriate statistical methods were used to analyze the data to fulfil the objectives. Graph pad prism Results were expressed in mean \pm SD. Probability values of $\mathrm{P}<0.05$ were considered to be statistically significant.

\section{Results and Discussion}

\subsection{Phytochemical Screening}

Phytochemical screening is very important for determining biological compounds. The results showed that phenols, flavonoids, alkaloids, glycosides and tannins. This Phytochemical showed different biological activities which play an important role in the protection against chronic diseases.

\subsection{Anti-Hyperlipidemic Activities}

Body weight of rats was significantly increased when they were fed with high fat diet (HFD) for 4 weeks when compared with normal control. By inducing GCBE the body weight reduced significantly $(\mathrm{P}<0.05)$, when compared to normal and hyperlipidemic control and the results were expressed in Table 2 and Figure 1.

By administering the high fat diet to group 4 animals for 4 weeks continuously, the lipid levels get increased significantly. The dose of green coffee bean extract of $200 \mathrm{mg} / \mathrm{kg}$ and $400 \mathrm{mg} / \mathrm{kg}$ given orally and the serum lipid levels reduced 
Table 2. Effect of Canephora robusta on body weight and lipid profile.

\begin{tabular}{cccccccc}
\hline Groups & Weight & $\begin{array}{c}\text { Total } \\
\text { cholesterol }\end{array}$ & Triglycerides & $\begin{array}{c}\text { Low density } \\
\text { lipoprotein }\end{array}$ & $\begin{array}{c}\text { High density } \\
\text { lipoprotein }\end{array}$ & $\begin{array}{c}\text { Very low density Atherogenic } \\
\text { lipoproteins } \\
\text { index }\end{array}$ \\
\hline Normal Rats & $182.5 \pm 23.6$ & $23.6 \pm 67$ & $142.9 \pm 9.1$ & $26.7 \pm 38$ & $33.1 \pm 4.06$ & $26.5 \pm 2.07$ & 0.71 \\
Hyperlipidemic Rats & $222.5 \pm 18.9$ & $52.2 \pm 3$ & $235.9 \pm 1.6$ & $172.05 \pm 3.1$ & $27.1 \pm 3.9$ & $52.2 \pm 2.0$ & 1.92 \\
Standard (Atorvastatin) & $165 \pm 19.1$ & $45.7 \pm 2.2$ & $276.6 \pm 10.7$ & $180.7 \pm 4.1$ & $40.8 \pm 1.7$ & $46.7 \pm 2.6$ & 1.12 \\
Ethanolic extract $200 \mathrm{mg} / \mathrm{kg}$ & $165 \pm 5.7$ & $35.2 \pm 4.8$ & $146.3 \pm 3.8$ & $163.5 \pm 0.8$ & $33.7 \pm 2.4$ & $35.6 \pm 2.7$ & 0.91 \\
Ethanolic extract $400 \mathrm{mg} / \mathrm{kg}$ & $162 \pm 19.1$ & $35.4 \pm 3.5$ & $186.1 \pm 4.7$ & $65.5 \pm 1.4$ & $38.8 \pm 15$ & $35.3 \pm 2.7$ & 1.04 \\
\hline
\end{tabular}

Values are expressed as Mean \pm SD using ANOVA.

\section{Effect of Ethanolic Extract of C.robusta on Atherogenic diet induced Rats}

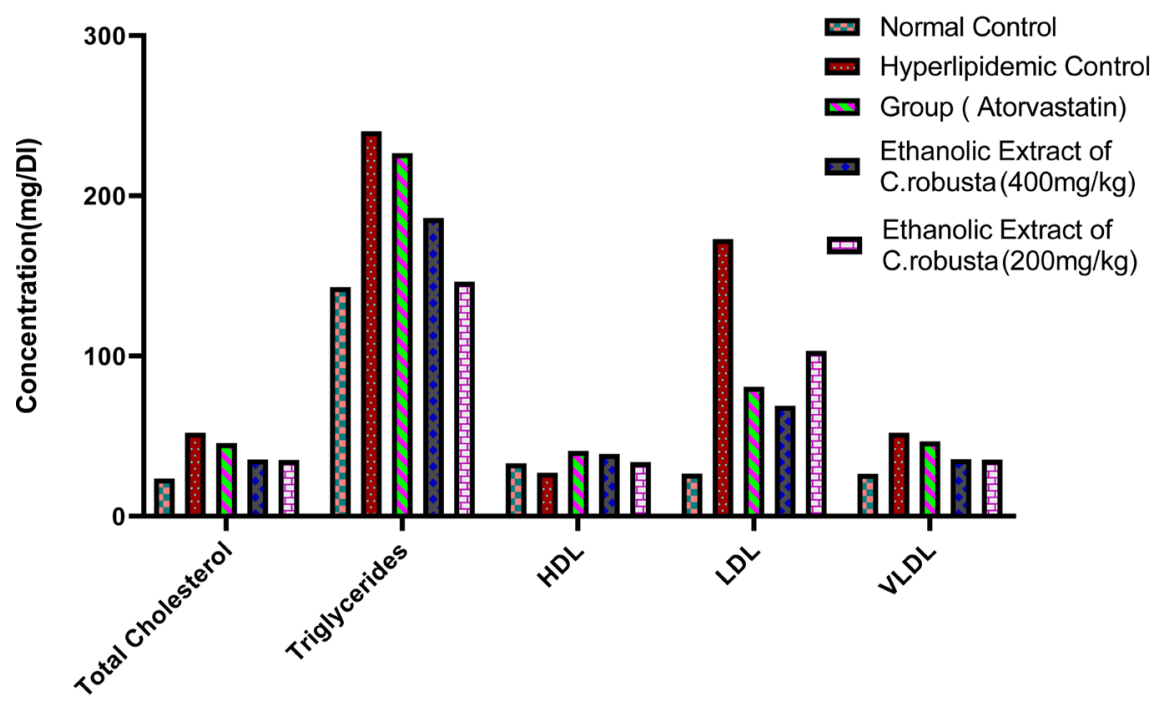

Figure 1. Effect of C. robusta on atherogenic diet induced rats.

significantly by $(\mathrm{P}<0.05)$. The HDL levels get decreased by inducing the obesity by HFD for 4 weeks. So, this green coffee bean given at $200 \mathrm{mg} / \mathrm{kg}$ and 400 $\mathrm{mg} / \mathrm{kg}$ shows the significant increase in the HDL in the body shown in Figure 1 and the atherogenic index of the treated group was reduced when compared with Hyperlipidemic group in Figure 2. So, the following results have shown the effect of the drug which leads to decrease the serum lipid levels and body weight of obese rats. Moreover, the previous studies on Canephora robusta on anti-hyperlipidemic activity with methanolic extract at doses of 100 and $200 \mathrm{mg} / \mathrm{kg}$ also shown the significant decrease of body weight, lipid levels like LDL, VLDL, TC, Triglycerides and increase in the HDL levels [17]. Bong keun et al. confirmed that the active compound 3-CQA from GCBE, reduces body fat accumulation by the regulation of adipogenesis and lipogenesis in obesity. Thus, those findings demonstrate that GCBE represents a potential activity that prevents the development of obesity, hyperlipidemia and its complications in diseases [18]. Our present study shows the significant decrease of weight and lipid levels were better than previous studies because of high dose and more effectiveness. 


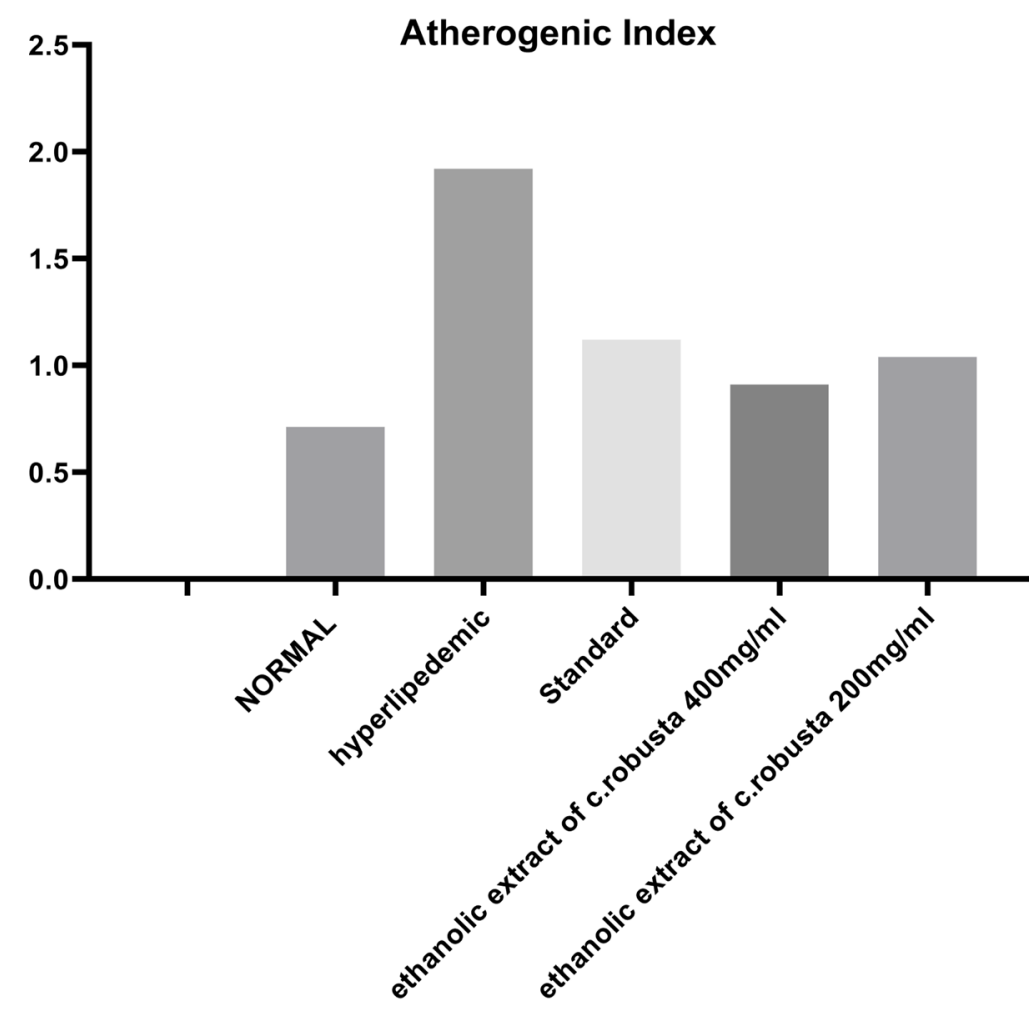

Figure 2. Effect of ethanolic extract of C. robusta on atherogenic diet index of rats.

\section{Conclusion}

The main aim of study is to show the significant anti-obesity and anti-hyperlipidemic activity of the plant. This was conducted to determine that Canephora robusta can act as anti-hyperlipidemic agent which was proven by many researchers. They were determined that their plant was reduced body weight in previous studies. Here, study was performed to determine effective dose and the amount of a dose which is safe to reduce body weight.

\section{Acknowledgements}

Authors are grateful to Vaageswari Educational Society, Karimnagar, and Telangana, India for providing infrastructure and research facilities.

\section{Authors' Contributions}

All the authors have contributed equally.

\section{Conflicts of Interest}

The authors declare no conflicts of interest regarding the publication of this paper.

\section{References}

[1] Wanderley, A.B. (2017) Functional Benefits of Green Coffee in Metabolic Syndrome Prevention: A Review Study. Journal of Chemical and Pharmaceutical Research, 9, 
5-12.

[2] WHO (2015) Obesity and Overweight Fact Sheet.

[3] Uptodate.com (2005) R Rosenson-UpToDate. Up to Date, Wellesley.

[4] Levy, R.I. and Fredrigkson, D.S. (1968) Diagnosis and Management of Hyperlipoproteinemia. The American Journal of Cardiology, 22, 576-583.

[5] (2019) What Is Green Coffee Bean Uses and Benefits. https://vitagene.com

[6] Dagoon, J. (2005) Agriculture \& Fishery Technology IV. Rex Bookstore, Inc., Manila, 58 .

[7] Kathleen Davis, F.N.P. (2015) Article, 295385. Medical News Today.

[8] O’Keefe Osborn, C. (2017) What We Should Know about Hyperlipidemia.

[9] Diabetis.co UK (2013) Green Coffee Bean Extract Has Anti-Diabetic Benefits.

[10] Tanaka, K., Nishizono, S., Tamaru, S. and Kondo, M. (2009) Anti-Obesity and Hypotriglyceridemic Properties of Coffee Bean Extract in Sprague Dawley Rats. Food Science and Technology Research, 15, 147-152. https://doi.org/10.3136/fstr.15.147

[11] Dong, W. (2015) Characterization of Fatty Acid, Amino Acid and Volatile Compound Compositions and Bioactive Components of Seven Coffee (Coffea robusta) Cultivars Grown in Hainan Province China. Molecules, 20, 16687-16708. https://doi.org/10.3390/molecules200916687

[12] Affonso, R.C.L., Voytena, A.P.L. and Maraschin, M. (2016) Phytochemical Composition, Antioxidant Activity, and the Effect of the Aqueous Extract of Coffee (Coffea arabica L.) Bean Residual Press Cake on the Skin Wound Healing. Oxidative Medicine and Cellular Longevity, 2016, Article ID: 1923754. https://doi.org/10.1155/2016/1923754

[13] McNaugh, A.D. and Wilkinson, A. (1997) Compendium of Chemical Terminology. 2nd Edition, Blackwell Scientific Publications, Oxford.

[14] Khandelwal, K.R. (2008) Practical Pharmacognosy. Nirali Prakashan Publications.

[15] Prashar, Y., Gandhare, B. and Mendhe, B. (2010) Anti-Hyperlipidemic Activity of Bauhinia Variegate Root Extracts. International Journal of Biomedical and Advance Research, 1, 96-102. https://doi.org/10.7439/ijbar.v1i3.7

[16] OECD Guideline for Testing of Chemicals, Acute Oral Toxicity-Acute Toxic Class Method.

[17] Blum, J., Lemaire, B. and Lafay, S. (2007) Effect of a Green Decaffeinated Coffee Extract on Glycaemia: A Pilot Prospective Study. Nutrafoods, 6, 13-17.

[18] Choi, B.-K., Park, S.-B. and Lee, B.-R. (2016) Green Coffee Bean Extract Improves Obesity by Decreasing Body Fat in High Fat Diet Induced Obese Mice. Asian Pacific Journal of Tropical Medicine, 9, 635-643. https://doi.org/10.1016/j.apjtm.2016.05.017 